\title{
An observation of roll waves in a supraglacial meltwater channel, Harlech Gletscher, East Greenland
}

\author{
Steve Carver, \\ School of Geography, University of Leeds, Leeds LS2 9JT, England \\ DAVE SEAR, \\ Department of Geography, University of Southampton, Southampton SO9 5NH, England \\ ERIC VALENTINE \\ Department of Civil Engineering, University of Newcastle-upon-Tyne, Newcastle-upon-Tyne NE1 7RU, England
}

\begin{abstract}
Observations of pulsating flow conditions in a supraglacier meltwater channel on Harlech Gletscher, East Greenland, are reported. Waves of water with turbulent wave fronts and smooth recessive limbs were observed passing downstream at regular intervals of 6-7 s. Peak channel discharge was estimated at $0.5-1.0 \mathrm{~m} \mathrm{~m}^{3} \mathrm{~s}^{-1}$, in between which discharge was zero. It is suggested that the phenomenon as observed was due to the formation of roll waves in response to channel morphology and prevalent discharge conditions. Measurements of channel morphology are given together with calculations of critical flow conditions, supporting the hypothesis of roll waves in a natural ice channel. A brief introduction to roll waves and the theory regarding their formation is included.
\end{abstract}

\section{INTRODUGTION}

In early August 1989, marked pulsating flow conditions were observed in a supraglacial meltwater channel on Harlech Gletscher in the Berserkerbræ region of North Staunings Alper, East Greenland. The time between discharge peaks at the point of observation (estimated at between 0.5 and $1.0 \mathrm{~m}^{3} \mathrm{~s}^{-1}$ ) was measured at $6-7 \mathrm{~s}$, in between which discharge was zero. This was due to the formation of roll waves in response to channel morphology and prevalent discharge conditions.

Fluctuation of the discharge over time in supraglacial meltwater streams is common. The time-scale of variations in a channel discharge vary between small changes on a short time-scale measured in seconds or minutes due, it is thought, to the release of water pockets in the glacier (Golubev, 1973) to larger variations over a matter of days in response to changes in prevailing weather conditions (e.g. Gudmundsson and Sigbjarnarson, 1972). Diurnal fluctuations in meltwater discharge are perhaps the most marked variations, though only during the summer period and especially during the late summer when ablation rates are highest. None of the fluctuations referred to above, however, can account for the regular, short-term, large-scale fluctuations in discharge of the type described here, although normal fluctuations may exert a strong local influence

The following paper gives a short description of the phenomenon as observed, measurements made at the time of observation, an outline of the theory of roll-wave formation, supporting calculation and a brief discussion.

\section{LOGATION AND DESGRIPTION OF HARLECH GLETSCHER}

Harlech Gletscher is located at approximately $72^{\circ} 10^{\prime} \mathrm{N}$, $24^{\circ} 40^{\prime} \mathrm{W}$ in the northeast corner of Stauning Alper where it forms a tributary of Berserkerbra (see Fig. 1). Staunings Alper comprises an area of mainly granitic intrusions into Cambrian and Precambrian rocks enclosed roughly by Kong Oscars Fjord to the north, Nordvestfjord to the south, Skeldal and Schuchert Dal to the east and Nathorst Land to the west. These mountains can be described as being typical Arctic alpine in character (Sugden and John, 1979).

Harlech Gletscher lies between 700 and $1300 \mathrm{~m}$ a.s.l. with a west-east orientation in direction of flow. The glacier is approximately $5 \mathrm{~km}$ long and is fed by two main cirque glaciers at its head. The glacier surface has a relatively even gradient at the point of observation (slope $=0.05)$ with little evidence of crevassing.

\section{OBSERVATIONS OF PULSATING FLOW}

At the time of observation, pulses of meltwater (with an estimated peak discharge of $0.5-1.0 \mathrm{~m}^{3} \mathrm{~s}^{-1}$ ) were passing rapidly downstream at intervals of $6-7 \mathrm{~s}$ between peaks 


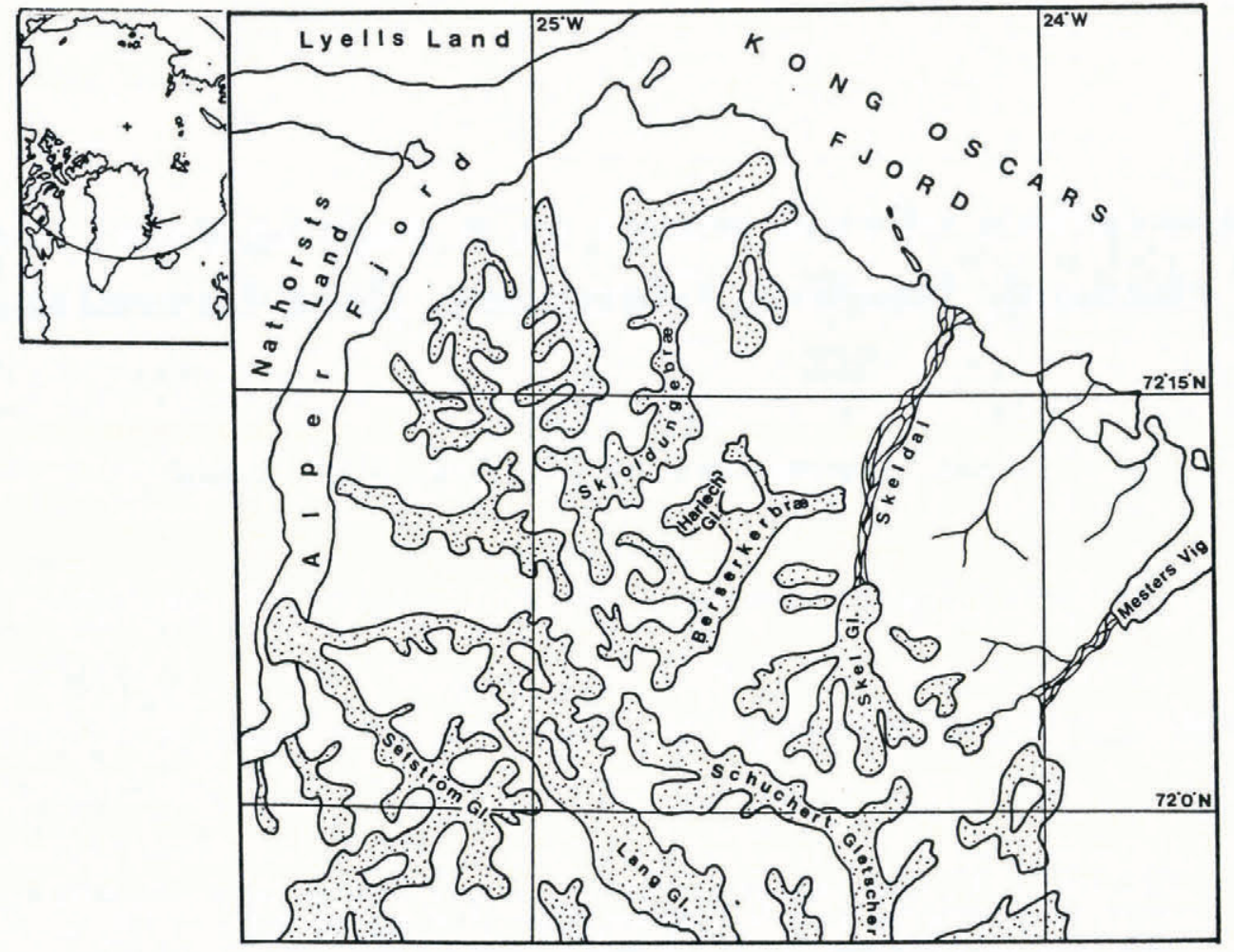

Fig. 1. North Stauning Alper, East Greenland, showing the position of Harlech Gletscher. Inset: general location.

(averaged over $15 \mathrm{~min}$ ). At minimum discharge between peaks, the channel was empty with the exception of a small amount of run-off from the channel banks and sides together with the water retained in channel pools.

The wave front of each pulse was noted to be turbulent. The turbulent wave front and empty channel immediately in front of the advancing wave are clearly shown in Figure 2. The point at which the photograph (Fig. 2) was taken shows a wave front advancing over a riffle, with the main body of the wave occupying the upstream pool. The high-water mark also visible on the left bank of the riffle in the foreground of Figure 2 may give some indication of the water depth at the peak discharge.

The channel itself was noted to be gently sinuous (sinuosity $=1.43$ ) and of near-uniform cross-section. The longitudinal section was marked by a smooth undulating bed form analogous to pools and riffles. This is shown in Figure 3. The time of observation was $1800 \mathrm{~h}$ local time (roughly at the peak in diurnal fluctuation of discharge due to solar heating). Investigation of the channel and catchment area upstream revealed no obvious siphon feature and, furthermore, the "pulsating" effect decreased with distance upstream such that zero discharge between peaks was no longer observed. Accurate measurements of the catchment area of the channel and its upstream length are made difficult by a lack of large-scale maps and/or aerial-photograph coverage but are estimated from $1: 250000$ maps to be in the order of $5 \mathrm{~km}^{2}$ and $3 \mathrm{~km}$, respectively.

The exact duration of pulsating-flow conditions is not known, though it was observed for $30 \mathrm{~min}$ with no obvious change in either wave-timing or peak discharge. However, observations made $16 \mathrm{~h}$ later (i.e. $1000 \mathrm{~h}$ the

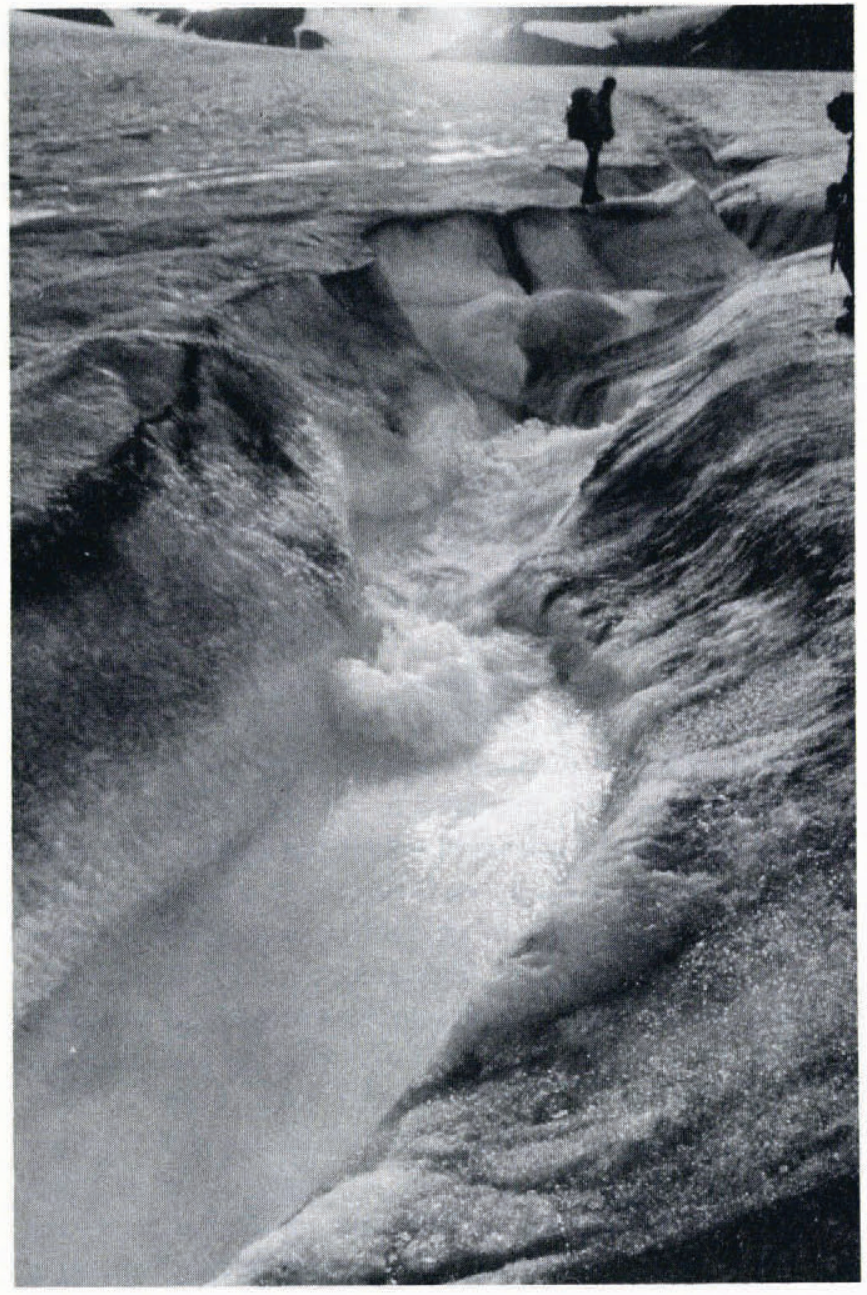

Fig. 2. Roll waves in a supraglacial meltwater channel, Harlech Gletscher, East Greenland. 
PLANFORM

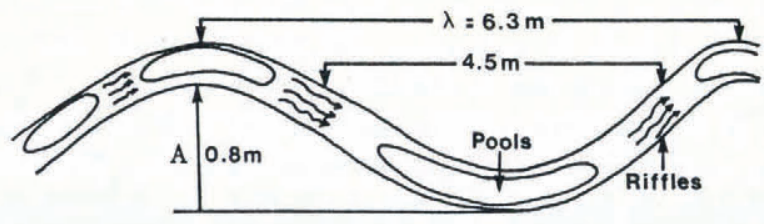

Mean channel slope $=5 \%$

AVERAGE CROSS-SECTION

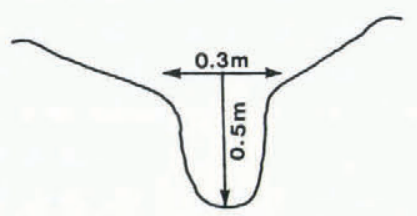

HYDROGRAPH (SCHEMATIC)

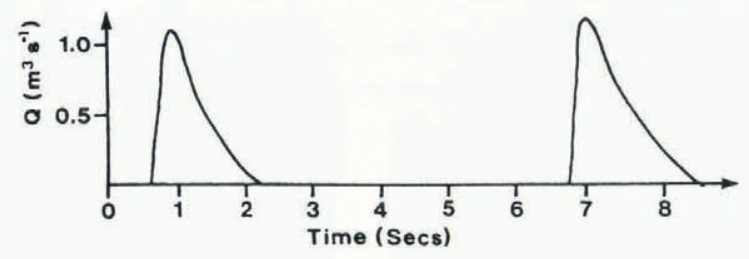

Fig. 3. Channel morphology and schematic roll-wave hydrograph.

following day) at the same location revealed that pulsating flow had ceased and normal flow conditions had resumed.

Basic measurements of the channel morphology were made using the rudimentary equipment available and averaged over a $100 \mathrm{~m}$ reach. Proper equipment for surveying and hydrological measurements was not available, since the time spent by the expedition in Staunings Alper was purely for the achievement of mountaineering objectives. These measurements are summarized in Figure 3 and, although rough, due to the nature of their measurement, are used as the basis of the tentative calculations given below.

\section{THEORY AND GALGULATIONS SUPPORTING ROLL-WAVE FORMATION}

Roll waves are more or less regular surges of water, each somewhat like a section of a gradually varied flow profile ending in a bore (Townson, 1990). These form when uniform flow in inclined channels becomes unstable due to very high flow velocities and/or a very steep channel gradient. This instability is characterized by the formation of a series of roll waves as uniform flow breaks down into travelling waves or pulsating flow (Chow, 1973). Thomas (1940) described pulsating flow as consisting of two parts, a turbulent head or wave front and a smooth tail section. This can be clearly seen in Figure 2. This turbulent wave front is a result of the velocity of the wave being greater than that of the surface flow adjacent to the channel bed and sides, giving rise to a breaking wave.

Roll waves were first reported by Cornish (1910) and have been studied experimentally and analytically by Jeffreys (1925). Attention has been focused on roll waves mainly in artificial channels such as inclined flumes and spillways, partly on account of their liability to overtop channel sides (Mayer, 1961). Most of these studies, therefore, relate to rectangular sections.

The following calculations and reasonings are presented in support of roll-wave formation in natural ice channels as described above for Harlech Gletscher, East Greenland.

The observed discharge $(Q)$ at the wave peak has been estimated at $0.5-1.0 \mathrm{~m}^{3} \mathrm{~s}^{-1}$ and the channel slope $\left(S_{0}\right)$ measured at 0.05 . The friction slope of the channel $\left(S_{\mathrm{f}}\right)$ may be expressed as:

$$
S_{\mathrm{f}}=(K \mathrm{Fr})^{2}
$$

where $S_{\mathrm{f}}=$ friction slope (which for uniform flow approximates to $\left.S_{0}\right) ; K=$ relative roughness for ice channels $\left(0.1 k R^{-1}\right.$ ) (see Townson, 1990, p. 118); $k=$ roughness height (effective height of irregularities forming roughness elements); $R=$ hydraulic radius (where $R=A / p) ; \mathrm{Fr}=$ Froude number $(U / \sqrt{g d}) ; U=$ calculated velocity $\left(\mathrm{m} \mathrm{s}^{-1}\right) ; g=$ acceleration due to gravity $\left(9.82 \mathrm{~m} \mathrm{~s}^{2}\right) ; d=$ water depth $(\mathrm{m}) ; A=$ cross-section area $\left(\mathrm{m}^{2}\right) ; p=$ wetted perimeter $(\mathrm{m})$.

Consequently, for amplification of a disturbance which would lead to the formation of a roll wave not only should Fr $>2$ but also that:

$$
K^{2}<S_{0} / \mathrm{Fr}^{2} .
$$

Taking the lower limit of $\mathrm{Fr}$ as 2 (the minimum for rollwave formation), as shown by Stoker (1957), this gives:

$$
K^{2}<S_{0} / 4 \text {. }
$$

Considering the ice channel on Harlech Gletscher, where a likely range of values for roughness would be $0.001-0.003 \mathrm{~m}$ and with flow depths of $0.2-0.5 \mathrm{~m}$, then $K$ would be approximately $0.0005-0.0006$. Thus, for the observed channel slope $\left(S_{0}\right)$ of 0.05 , then:

$$
\begin{aligned}
S_{0} / \mathrm{Fr}^{2} & =0.05 /(2)^{2} \\
& =0.0125 .
\end{aligned}
$$

The criterion that $K^{2}<S_{0} / \mathrm{Fr}^{2}$ is therefore satisfied for the ice channel in question.

For non-rectangular sections, the requirement for rollwave formation is expressed as (after Townson, 1990):

$$
U \geq \alpha c
$$

where $U=$ calculated velocity $\left(\mathrm{m} \mathrm{s}^{-1}\right), \alpha=$ the Escoffier coefficient (usually $>2$ ) and $c=$ wave (disturbance) celerity $(\sqrt{g d})$.

If the range of values for Manning's " $n$ " for ice of $0.01-0.012$ (Chow, 1973) is applied to the observed flow depths of $0.2-0.5 \mathrm{~m}$, then the calculated velocity $(U)$ from Manning's equation:

$$
U=1 / n\left(R^{\frac{2}{3}} S_{0^{\frac{1}{2}}}\right)
$$


falls in the range of $3.5-5.25 \mathrm{~m} \mathrm{~s}^{-1}$. The use of the Manning equation to derive peak-flow velocities is an approximation for a steep channel but it does agree with the range of observed discharges $\left(0.5-1.0 \mathrm{~m}^{3} \mathrm{~s}^{-1}\right)$ which yield calculated velocities of $3.3-6.7 \mathrm{~m} \mathrm{~s}^{-1}$ for the average channel cross-section (averaged over three pools and three riffles) given in Figure 3. The wave celerity (c) for this range of depths is $1.4-2.21 \mathrm{~m} \mathrm{~s}^{-1}$. Therefore, the criterion that $U \geq 2 c$ is also satisfied. It is also noted that the Froude number $(\mathrm{Fr})$ would lie in the region of 2.372.5 , thus $\mathrm{Fr}>2$, which satisfies the initial condition for roll-wave formation and supports the hypothesis of rollwave development in a natural ice channel.

However, further field observations and more accurate measurements may be required to confirm or reject the hypothesis of roll waves as an explanation of the observed phenomenon.

\section{DISGUSSION AND GONGLUSIONS}

From the numerical analyses above, together with direct observation in the field, it may be concluded that the phenomenon observed was due to the formation of roll waves. The critical conditions controlling roll-wave formation (channel slope, flow velocity and depth) are satisfied for the channel on Harlech Gletscher. Conditions of steep slope, high flow velocity and depth create uniform flow conditions which then break down into unstable flow (manifested here in the form of roll waves) as one or more of the controlling factors increases past the critical point (i.e. flow is said to be in a supercritical state and so becomes unstable). The steep nature of the channel $\left(S_{0}=0.05\right)$ and the very low Manning's " $n$ " for ice $(0.01-0.012)$ give rise to high flow velocities $(U=3.3-$ $\left.6.7 \mathrm{~m} \mathrm{~s}^{-1}\right)$, whilst the time of observation near peak discharge due to solar heating provided sufficient depth of water in the channel for uniform flow to become unstable.

The behaviour of roll waves is strongly threedimensional and, once conditions allow their formation, their spatial frequency seems to be strongly linked with that of upstream disturbances. In this instance, it is likely that channel morphology in terms of its gently sinuous planform and smooth pool-riffle longitudinal section, together with prevalent discharge conditions, had a significant effect in accentuating wave formation. It is also possible that a progressive steepening of Harlech Gletscher as it descends to meet Berserkerbræ may have an effect both in increasing the channel slope and flow velocity, giving rise to unstable flow conditions.

It is suggested, on the basis of the field observations and calculations given above, that conditions commonly found in supraglacial meltwater channels may mitigate against the formation of roll waves in most instances. These include an increase in sinuosity and variation in the longitudinal profile of ice channels (i.e. moulins, waterfalls, crevasses, etc.), causing increased resistance and in-channel turbulence (accentuated by the presence of loose ice blocks and rock debris) and reduced flow velocity leading to non-uniform flow. Where roll waves do form, their occurrence is likely to be temporal, depending on diurnal fluctations in discharge such that for a given channel slope, relative roughness, etc. they form only when discharge is sufficient to provide the depth and velocity of water for uniform flow to develop and then become unstable. Conditions favouring the development of roll waves in supraglacial channels are therefore likely to be rare, as several factors compound to reduce the Froude number of the channel to $\mathrm{Fr}<2$.

\section{REFERENCES}

Chow, V.T. 1973. Open-channel hydraulics. London, McGraw Hill.

Cornish, V. 1910. Waves of the sea and other waves. London, Fisher Unwin.

Golubev, G.N. 1973. Analysis of the run-off and flow routing for a mountain glacier basin. International Association of Scientific Hydrology Publication 95 (Symposium at Cambridge $1969-$ Hydrology of Glaciers), 41-50.

Gudmundsson, G. and G. Sigbjarnarson. 1972. Analysis of glacier runoff and meteorological observations. F. Glaciol., 11(63), 303-318.

Jeffreys, H. 1925. The flow of water in an inclined channel of rectangular section. Philos. Mag., 6(49), 793-807.

Mayer, P.G.H. 1961. Roll waves and slug flows in inclined open channels. Trans. Am. Soc. Cit. Eng., 126, 505.

Stoker, J.J. 1957. Water waves; the mathematical theory with applications. New York, Interscience.

Sugden, D. E. and B.S. John. 1979. Glaciers and landscape; $a$ geomorphological approach. London, Edward Arnold.

Thomas, H.A. 1940. The propagation of waves in steep prismatic conduits. Studies in Engineering Bulletin (Iowa), 20, 214-229.

Townson, J. M. 1990. Free surface hydraulics. London, Unwin Hyman.

The accuracy of references in the text and in this list is the responsibility of the authors, to whom queries should be addressed. 